\title{
Communication \\ E-Cadherin Orthologues as Substrates for the Serine Protease High Temperature Requirement A (HtrA)
}

\author{
Sabine Bernegger ${ }^{1}$, Evelyn Hutterer ${ }^{1}$ (D), Urszula Zarzecka ${ }^{2}$, Thomas P. Schmidt ${ }^{1}$, Markus Huemer ${ }^{1}$ (D), \\ Isabella Widlroither ${ }^{1}$, Gernot Posselt ${ }^{1}$ (D) Joanna Skorko-Glonek ${ }^{2} \mathbb{D}$ and Silja Wessler ${ }^{1,3, *(\mathbb{D})}$
}

1 Department of Biosciences and Medical Biology, Division of Microbial Infection and Cancer, Paris-Lodron University of Salzburg, 5020 Salzburg, Austria; sabine.bernegger@plus.ac.at (S.B.); evelyn.hutterer@plus.ac.at (E.H.); thomas.phi.schmidt@gmail.com (T.P.S.); markus.huemer1991@me.com (M.H.); isabella.widlroither@plus.ac.at (I.W.); gernot.posselt@plus.ac.at (G.P.)

2 Department of General and Medical Biochemistry, Faculty of Biology, University of Gdańsk, 80-308 Gdańsk, Poland; urszula.zarzecka@ug.edu.pl (U.Z.); joanna.skorko-glonek@biol.ug.edu.pl (J.S.-G.)

3 Cancer Cluster Salzburg and Allergy Cancer BioNano Research Centre, University of Salzburg, Hellbrunner Strasse 34, 5020 Salzburg, Austria

* Correspondence: silja.wessler@plus.ac.at; Tel.: +43-662-8044-7210

\section{check for} updates

Citation: Bernegger, S.; Hutterer, E.; Zarzecka, U.; Schmidt, T.P.; Huemer, M.; Widlroither, I.; Posselt, G.; Skorko-Glonek, J.; Wessler, S. E-Cadherin Orthologues as Substrates for the Serine Protease High Temperature Requirement A (HtrA). Biomolecules 2022, 12, 356 https://doi.org/10.3390/ biom12030356

Academic Editor: Mark S. Johnson

Received: 29 January 2022

Accepted: 22 February 2022

Published: 24 February 2022

Publisher's Note: MDPI stays neutral with regard to jurisdictional claims in published maps and institutional affiliations.

Copyright: (C) 2022 by the authors. Licensee MDPI, Basel, Switzerland. This article is an open access article distributed under the terms and conditions of the Creative Commons Attribution (CC BY) license (https:// creativecommons.org/licenses/by/ $4.0 /)$

\begin{abstract}
Helicobacter pylori (H. pylori) expresses the serine protease and chaperone High temperature requirement $\mathrm{A}(\mathrm{H} \operatorname{tr} \mathrm{A})$ that is involved in periplasmic unfolded protein stress response. Additionally, H. pylori-secreted HtrA directly cleaves the human cell adhesion molecule E-cadherin leading to a local disruption of intercellular adhesions during pathogenesis. HtrA-mediated E-cadherin cleavage has been observed in response to a broad range of pathogens, implying that it is a prevalent mechanism in humans. However, less is known whether E-cadherin orthologues serve as substrates for bacterial HtrA. Here, we compared HtrA-mediated cleavage of human E-cadherin with murine, canine, and simian E-cadherin in vitro and during bacterial infection. We found that HtrA targeted mouse and dog E-cadherin equally well, whereas macaque E-cadherin was less fragmented in vitro. We stably re-expressed orthologous E-cadherin (Cdh1) in a CRISPR/Cas9-mediated cdh1 knockout cell line to investigate E-cadherin shedding upon infection using $H$. pylori wildtype, an isogenic $h t r A$ deletion mutant, or complemented mutants as bacterial paradigms. In Western blot analyses and superresolution microscopy, we demonstrated that $H$. pylori efficiently cleaved E-cadherin orthologues in an HtrA-dependent manner. These data extend previous knowledge to HtrA-mediated E-cadherin release in mammals, which may shed new light on bacterial infections in non-human organisms.
\end{abstract}

Keywords: HtrA; E-cadherin; infection; pathogens

\section{Introduction}

Cadherins are key players in cell adhesion, regulation of tissue organization and morphogenesis [1]. In epithelial cells, E-cadherin represents a crucially important molecule in the establishment of intercellular adhesions and functions as a tumor suppressor. The domain structure of E-cadherin is characterized by an extracellular domain (EC), a transmembrane (TM) domain, and an intracellular domain (IC). The extracellular domain contains five tandemly repeated sequences (EC1-5). Calcium ions bind to negatively charged motifs located between the $\mathrm{EC}$ repeats to provide the adhesive properties of E-cadherin. The calcium-bound ectodomains of E-cadherin interact in trans with E-cadherin from opposing cells and in cis on the same cell, respectively, leading to the formation of connective dimers and E-cadherin clustering [2,3]. The IC domain of E-cadherin recruits cytoplasmic signaling proteins, including $\beta$-catenin and p120-catenin, which control the strength and integrity of the adhesion complex and regulate downstream signaling transduction pathways implicated in the actin cytoskeleton reorganization and cancer-associated gene transcription $[4,5]$. 
E-cadherin-based cell adhesion is a dynamic process. Cytoplasmic signal transduction pathways can interfere with the integrity of cadherin complexes leading to disruption of the cell adhesion machinery [6,7]. Further, downregulation of E-cadherin expression via transcriptional repression, loss-of-function mutations, or extracellular shedding have been connected with alterations at adhesive interfaces implicated in a variety of cellular processes such as cell polarity, proliferation, survival, and invasive growth [8-11]. A number of cellular proteases, including activated A Disintegrin And Metalloproteinase domaincontaining protein 10 (ADAM10) or the matrix metalloproteinases MMP-3 and MMP-7, have been described that cleave-off the EC domain of E-cadherin on the cell surface $[10,11]$. In addition to these host factors, bacteria-derived serine proteases were identified as potent E-cadherin proteases with crucial roles in the progression of infectious diseases. Almost all bacteria express at least one homologue of the evolutionary conserved serine protease and chaperone High temperature requirement A (HtrA) family [12]. In Escherichia coli (E. coli), the HtrA proteases DegP, DegQ, and DegS serve as structural paradigms for HtrA proteins expressed by Gram-negative bacteria [13]. DegP and DegQ consist of an N-terminal signal peptide, which is responsible for periplasmic localization followed by a protease domain harboring the catalytic triad composed of histidine, serine, and aspartate residues. In the C-terminal region, DegP and DegQ contain two PDZ (postsynaptic density protein [PSD95], Drosophila disc large tumor suppressor [Dlg1], and zonula occludens-1 protein [ZO-1]) domains mediating protein-protein interactions, substrate recognition and substrate binding $[14,15]$. The activity of HtrA proteins is dependent on the formation of multimeric structures consistent of trimers as building blocks. HtrA assembles into inactive hexameric oligomers that are converted into proteolytic active oligomers consisting of 12-24 HtrA monomers upon substrate binding $[15,16]$.

HtrA proteins were discovered as determinants in virulence of bacterial pathogens. The human class-I carcinogen Helicobacter pylori (H. pylori) secretes HtrA into the environment and mediates E-cadherin ectodomain cleavage [17-19]. In addition to the HtrA substrate E-cadherin, $H$. pylori HtrA also targets the tight junction proteins claudin- 8 and occludin [20] as well as the desmosomal cadherin desmoglein-2 [21], implying that the main function of extracellular HtrA is to open intercellular adhesions of polarized epithelial cells. Consequently, $H$. pylori can transmigrate across the epithelium and translocate the virulence factor cytotoxin-associated gene $\mathrm{A}(\mathrm{CagA})$ at the basolateral domain of polarized epithelial cells [20]. HtrA proteins are expressed by many organisms. The human pathogens Campylobacter jejuni, Salmonella enterica, enteropathogenic Escherichia coli (EPEC), Proteus mirabilis, or Yersinia enterocolitica also target E-cadherin during infection [22-24], leading to the hypothesis that bacteria utilize HtrA proteases to promote infectious diseases via a local opening of intercellular adhesions [21].

Based on these previous findings, we hypothesize that HtrA-mediated E-cadherin cleavage is a prevalent mechanism, which is also implicated in the infection process in other mammals. Using H. pylori HtrA as a prime example for active HtrA proteases, we investigated the hypothesis that cleavage of E-cadherin from other species represents a gateway for bacterial pathogens in non-human organisms.

\section{Materials and Methods}

\subsection{Plasmids}

To generate the E-cadherin (Cdh1) expression constructs encoding species-specific

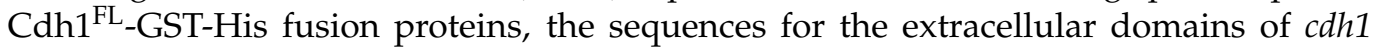
genes were amplified from the genomes of indicated animals (HsCdh1 from Homo sapiens, Asp155-Ala709, accession no. NP_004351.1 UniProt: P12830); ClCdh1 from Canis lupus familiaris, Asp157-Ala712, accession no. NP_001274054.1 UniProt: F1PAA9; MfCdh1 from Macaca fascicularis, Asp155-Ala709, accession no. XP_005592416.1 UniProt: A0A2K5V299; MmCdh1 from Mus musculus, Asp157-Ala711, accession no. NP_033994.1 UniProt: P09803) lacking the TM and the IC domains (Table 1). NheI/SacII or HindIII/SacII digested PCRgenerated inserts were ligated into a $\mathrm{pEGFPN}_{3}$-based expression vector and fused to a GST- 
and $\mathrm{His}_{6}$-double tag allowing purification and detection by Western blotting. Full length $c d h 1$ genes were cloned into the $\mathrm{pEGFPN}_{3}$ expression vector to express full length Cdh1 proteins C-terminally fused to GFP in eukaryotic cells (Table 1).

Table 1. Constructs used in the study.

\begin{tabular}{|c|c|c|c|}
\hline Constructs & aa & & Primer \\
\hline $\mathrm{HoCdh}_{1} \mathrm{EC} C \mathrm{CT} \mathrm{H}$ & $1-709$ & forward & 5'-GATCGCTAGCCACCATGGGCCCTTGGAG-3' \\
\hline Hscant-Gs1-His & $1-109$ & reverse & 5'-GATCCCGCGGTGGCAGGAATTTGCAATC-3' \\
\hline & & forward & 5'-GATCGCTAGCCACCATGGGCCCTCGGTAC-3' \\
\hline $\mathrm{ClCdh} 1^{\mathrm{EC}}$-GST-His & $1-712$ & reverse & $5^{\prime}$-GATCCCGCGGTGGCAGGAACCTGCAAG-3' \\
\hline $\mathrm{MfCdh}_{1}{ }^{\mathrm{EC}}$-GST-His & $1-709$ & forward & 5'-GATCGCTAGCCACCATGGGCCCTTGGAG-3' \\
\hline MIfCahl-GSI-His & $1-109$ & reverse & 5'-GATCCCGCGGTGGCAGGAACCTGCAAG-3' \\
\hline MmCdh1 ${ }^{\text {EC }}$-GST- & $1-711$ & forward & 5'-GATCAAGCTTCACCATGGGAGCCCGGTG-3' \\
\hline His & $1-711$ & reverse & 5'-GATCCCGCGGTGGCAGGAACTTGCAATC-3’ \\
\hline $\mathrm{HsCdh} 1^{\mathrm{FL}}-\mathrm{GFP}$ & $1-882$ & $\begin{array}{l}\text { forward } \\
\text { reverse }\end{array}$ & $\begin{array}{l}5^{\prime} \text {-GATCCCGCGGCTAATGATGATGATGATGATGATCCGATTTTGGAGGATG-3' } \\
\text { 5'-CTAGCCGCGGTGTCGTCCTCGCCG-3' }\end{array}$ \\
\hline $\mathrm{ClCdh}^{\mathrm{FL}}$-GFP & $1-885$ & $\begin{array}{c}\text { forward } \\
\text { reverse }\end{array}$ & $\begin{array}{l}\text { 5'-GATCGCTAGCCACCATGGGCCCTCGGTAC-3' } \\
\text { 5'-CTAGCCGCGGTGTCGTCCTCGCCACC-3' }\end{array}$ \\
\hline MfCdh1 $1^{\mathrm{FL}}-\mathrm{GFP}$ & $1-882$ & $\begin{array}{l}\text { forward } \\
\text { reverse }\end{array}$ & $\begin{array}{l}5^{\prime}-\text { GATCGCTAGCCACCATGGGCCCTTGGAG-3' } \\
5^{\prime}-\text { CTAGCCGCGGTGTCATCCTCGCCGC-3' }\end{array}$ \\
\hline $\mathrm{MmCdh}^{\mathrm{FL}}$-GFP & $1-884$ & $\begin{array}{l}\text { forward } \\
\text { reverse }\end{array}$ & $\begin{array}{l}\text { 5'-GATCAAGCTTCACCATGGGAGCCCGGTG-3' } \\
5^{\prime} \text {-CTAGCCGCGGTGTCGTCCTCACCACCG-3' }\end{array}$ \\
\hline
\end{tabular}

\subsection{Recombinant Proteins}

For the purification of recombinant glycosylated HsCdh1, ClCdh1, MfCdh1, or MmCdh1 containing a C-terminal GST-His 6 -tag, AGS cells were transfected for $16 \mathrm{~h}$ with plasmid DNA using polyethylenimine (PEI) in a 1:3 DNA:PEI ratio. The supernatant of transfected cells was collected every $24 \mathrm{~h}$ for the following 3 days, centrifuged at $350 \times g$ at $4{ }^{\circ} \mathrm{C}$ for $5 \mathrm{~min}$ and pooled in a sterile flask. Recombinant Cdh1-GST-His ${ }_{6}$-tagged proteins $^{-}$ were bound to glutathione sepharose beads (GE Healthcare Life Sciences, Vienna, Austria) and eluted with $10 \mathrm{mM}$ reduced glutathione (Carl Roth, Karlsruhe, Germany) for $16 \mathrm{~h}$ at $4{ }^{\circ} \mathrm{C}$. Finally, purified proteins were dialyzed in $50 \mathrm{mM}$ HEPES, pH 7.4, $150 \mathrm{mM} \mathrm{NaCl}$ and $900 \mu \mathrm{M} \mathrm{CaCl}_{2}$. Recombinant HtrA from H. pylori strain Hp26695 (HpHtrA, G18-K475, UniProt G2J5T2, EC 3.4.21.107) and its isogenic inactive mutant $\left(\mathrm{S}_{221} \mathrm{~A}\right)$ was purified as described previously [25]. Briefly, E. coli BL21 were transformed with an HtrA expression vector and grown in terrific broth (TB) medium to an $\mathrm{OD}_{600} \sim 0.7$ at $37{ }^{\circ} \mathrm{C}$. Expression of GST-HtrA was induced by addition of $100 \mu \mathrm{M}$ IPTG for $3 \mathrm{~h}$ at $30^{\circ} \mathrm{C}$. Bacteria were harvested by centrifugation, resuspended in PBS and lysed by sonication on ice 6 times for $30 \mathrm{~s}$ at 50\% power (Sonoplus Ultraschall Homogenisator HD270, Bandelin electronic $\mathrm{GmbH}$, Berlin, Germany). GST-tagged HtrA proteins were bound to glutathione sepharose beads (GE Healthcare Life Sciences, Vienna, Austria) and GST-tag was removed by addition of PreScission protease (GE Healthcare Life Sciences, Vienna, Austria) for $16 \mathrm{~h}$ at $4{ }^{\circ} \mathrm{C}$. Recombinant HtrA was eluted and dialyzed against $50 \mathrm{mM}$ HEPES (pH 7.4) and $150 \mathrm{mM}$ $\mathrm{NaCl}$. Purity of recombinant proteins is routinely checked with SDS-PAGE and staining with Coomassie Brilliant Blue G250 (Carl Roth, Karlsruhe, Germany).

\subsection{In Vitro Cleavage Assays}

For in vitro cleavage assays, $100 \mathrm{ng}$ recombinant Cdh1 proteins derived from Homo sapiens, Macaca fascicularis, Canis lupus familiaris, and Mus musculus were incubated with 20, $50,100,250,500$ or $1000 \mathrm{ng}$ active HtrA wt or $1000 \mathrm{ng}$ inactive HtrA S ${ }_{221} \mathrm{~A}$ (SA) in $50 \mathrm{mM}$ HEPES (pH 7.4), $150 \mathrm{mM} \mathrm{NaCl}$ and $0.5 \mathrm{mM}$ EGTA for $16 \mathrm{~h}$ at $37^{\circ} \mathrm{C}$. To analyze the kinetics, $100 \mathrm{ng}$ recombinant $\mathrm{Cdh} 1$ proteins were incubated with $250 \mathrm{ng}$ active HtrA wt or inactive HtrA SA for 1, 2, 4, 8 and $16 \mathrm{~h}$ at $37^{\circ} \mathrm{C}$ in $50 \mathrm{mM}$ HEPES (pH 7.4), $150 \mathrm{mM} \mathrm{NaCl}$ and $0.5 \mathrm{mM}$ EGTA. All in vitro cleavage reactions were performed in a total volume of $20 \mu \mathrm{L}$. 


\subsection{SDS-PAGE and Western Blot}

Protein samples obtained from in vitro cleavage or infection experiments were separated by SDS-PAGE and blotted on a nitrocellulose membrane. For detection of recombinant Cdh1 proteins, an antibody recognizing the $\mathrm{His}_{6}$-tag epitope (Rockland) was used. E-cadherin from whole cell lysates was detected with an antibody recognizing the highly conserved IC domain of E-cadherin (BD Transduction Laboratories ${ }^{\mathrm{TM}}$, Heidelberg, Germany). HtrA and CagA were detected using polyclonal sera. GAPDH (Cell Signaling Technology, Frankfurt, Germany) was used as a loading control for whole cell lysates.

\subsection{Mutagenesis of MKN-28 Cells}

For disruption of endogenous Cdh1 expression in MKN-28 cells, a specific oligonucleotide targeting exon ENSE00000844392 of hCdh1 was cloned into the guide RNA plasmid pX330-U6-Chimeric_BB-CBh-hSpCas9 [26]. For design of the single-guide RNA, an online tool made available by the Zhang laboratory of the Massachusetts Institute of Technology was used (Available online: http://CRISPR.mit.edu, accessed on 29 April 2014). The following oligonucleotides were synthesized, annealed, and inserted into the vector after BbsI digestion: gRNA_EC_n1_1/2: 5'-CAC CGC GCC GAG AGC TAC ACG TTC A and gRNA_EC_n1_2/2: 5' - AAA CTG AAC GTG TAG CTC TCG GCG C. Oligonucleotide synthesis and sequencing for confirmation of correct construct sequence was provided by Eurofins. MKN-28 cells were co-transfected with the plasmid pX330 carrying hSpCas9 and the guide RNA. Transfection was performed using PEI, with subsequent selection by incubation with medium containing $30 \mu \mathrm{g} / \mathrm{mL}$ blasticidin. Viable cells were consequently isolated, expanded and verified for Cdh1 expression by sequencing and Western blotting. For stable expression of orthologous Cdh1-GFP MKN-28 $\Delta c d h 1$ cells were seeded in 6-well plates at low confluency and incubated for $24 \mathrm{~h}$ at $37^{\circ} \mathrm{C}$ and $5 \% \mathrm{CO}_{2}$. Cells were transfected with linearized plasmids using lipofectamine 3000 (Thermo Fisher Scientific, Vienna, Austria) for $48 \mathrm{~h}$ according to the manufacturers protocol. Selection of transfected cells was performed with G418 disulfate (Sigma Aldrich, Vienna, Austria).

\subsection{Cell Culture and Infection Experiments}

The gastric epithelial cell lines MKN-28 expressing Cdh1-GFP orthologues were grown in RPMI-1640 (Sigma Aldrich, Vienna, Austria) supplemented with 10\% FCS (Biowest, Vienna, Austria), 1\% L-glutamine (Biowest, Vienna, Austria), 10 mM HEPES (Carl Roth, Karlsruhe, Germany), and $400 \mu \mathrm{g} / \mathrm{mL}$ G418 disulfate in a humidified atmosphere at $37^{\circ} \mathrm{C}$ and $5 \% \mathrm{CO}_{2}$. For infection experiments, cells were seeded in 6-well plates three days prior to infection. H. pylori strains P12 wild type (wt), N6 wt, N6 $\Delta$ trA and, N6 $\Delta$ tr $r$ A/htrA wt $[27,28]$ were cultured on agar plates containing $10 \%$ horse serum (Biowest, Vienna, Austria) under microaerophilic conditions at $37^{\circ} \mathrm{C}$ for $16 \mathrm{~h}$ before infection. Cells were washed extensively with PBS to remove G418 disulfate solution from the cells and cells were starved 60 min before infection. MKN-28 cells were infected with $H$. pylori P12 wt, N6 wt, N6 $\Delta h t r A, \mathrm{~N} 6 \Delta h t r A / h t r A$ wt at a MOI (multiplicity of infection) of 100 for $24 \mathrm{~h}$ or left untreated (mock). For preparation of whole cell lysates, MKN-28 cells were washed two times with PBS and harvested in lysis buffer $(20 \mathrm{mM}$ Tris $\mathrm{pH}$ 7.5, $1 \mathrm{mM}$ EDTA, $100 \mathrm{mM}$ $\mathrm{NaCl}, 1 \%$ Triton X-100, $0.5 \%$ DOC, $0.1 \%$ SDS, $0.5 \%$ NP- 40 ) supplemented with $1 \times$ PIT (protease inhibitor cocktail complete EDTA-free tablets, Roche), $1 \mathrm{mM}$ sodium molybdate, $20 \mathrm{mM}$ sodium fluoride, $20 \mathrm{mM} \beta$-glycerophosphate, $1 \mathrm{mM}$ sodium orthovanadate. Whole cell lysates were cleared from cell debris by centrifugation at $16,000 \times \mathrm{g}$ for $10 \mathrm{~min}$ at $4{ }^{\circ} \mathrm{C}$.

\subsection{Immunofluorescence and STED Microscopy}

For immunofluorescence, cells were seeded on poly-L-lysine (Sigma Aldrich, Vienna, Austria) coated cover slips (Carl Roth, Karlsruhe, Germany) and infected with H. pylori P12 wt, N6 wt, N6 $\Delta h t r A$, at a MOI of 50 for $24 \mathrm{~h}$ or left untreated (mock). Cells were washed twice with PBS containing $\mathrm{CaCl}_{2}$ and $\mathrm{MgCl}_{2}$ and fixed with ice-cold methanol at $-20{ }^{\circ} \mathrm{C}$ for $10 \mathrm{~min}$. To localize Cdh1, cells were stained with an antibody targeting the IC 
domain of E-cadherin (BD Transduction Laboratories ${ }^{\mathrm{TM}}$, Heidelberg, Germany), which is highly conserved in all Cdh1 variants. H. pylori was detected using a polyclonal serum raised against $H$. pylori lysate (gift from Rainer Haas, Munich) and nuclei were stained with 4',6-diamidino-2-phenylindole (DAPI) (Carl Roth, Karlsruhe, Germany). After incubation with secondary antibodies coupled to STAR-RED or STAR580 dyes (Abberior, Göttingen, Germany) cover slips were mounted on glass microscopy slides using antifade mounting medium (Abberior, Göttingen, Germany) and fluorescence was detected using a Zeiss Observer Z1 fluorescence microscope equipped with an Abberior Instruments STEDYCON unit for confocal and super-resolution STED microscopy.

\subsection{Colony-Forming Unit Assay}

MKN-28 cells were infected with $H$. pylori P12 wt, N6 wt and N6 $\Delta h t r A$ and N6 $\Delta h \operatorname{tr} A / h t r A$ wt at MOI 50 for $6 \mathrm{~h}$. To remove unbound bacteria, cells were washed 3 times with pre-warmed PBS and incubated in lysis solution (PBS containing $0.05 \%$ saponin) for $15 \mathrm{~min}$ at $37{ }^{\circ} \mathrm{C}$ and $5 \% \mathrm{CO}_{2}$. The resulting suspension was diluted in 10 -fold serial steps and three appropriate dilutions were plated on GC agar plates in duplicates. After 3-5 days of incubation under microaerophilic conditions, the number of cell-bound bacteria was quantified as colony forming units (CFU). The cell binding assay was repeated four times.

\subsection{Statistical Analysis}

Statistical analysis of the adherence assay was performed using ordinary one-way ANOVA and the Tukey's post hoc test with the GraphPad Prism software (version 8.0.2). Four independent experiments were analyzed. $p$ values $>0.05$ were not considered as statistically significant. Densitometric quantification of cadherin full-length bands was performed with the ImageLab Software (version 3.0.1) and are expressed as mean percentage \pm SD, with E-cadherin treated with inactive HtrA SA set to $100 \%$. Statistical analysis was performed on raw data using the student's $t$-test (paired two tailed). Three independent experiments were analyzed. $p$ values $>0.05$ were not considered statistically significant.

\section{Results and Discussion}

\subsection{HtrA Cleaves Different Cadherin Orthologues}

To investigate whether E-cadherin from other mammal species serves as an HtrA substrate, we selected E-cadherin (Cdh1) expressed by Macaca fascicularis (Mf), Canis lupus familiaris $(\mathrm{Cl})$, or Mus musculus $(\mathrm{Mm})$ and compared them with Cdh1 from Homo sapiens $(\mathrm{Hs})$ (Table 2). All Cdh1 orthologues share an N-terminal signal peptide (SP) and a downstream pro-peptide (PP) that are removed post-translationally during transport to the cell surface. The characteristic feature of all Cdh1 orthologues is the extracellular domain (EC), which consists of tandem repeats (EC1-EC5) with interspaced negatively charged amino acid sequence motifs DRE, DXNDNXP and DXD. These motifs bind calcium ions that are required for the adhesive properties of cadherin proteins $[29,30]$. The extracellular domain is followed by a short linker region, a transmembrane (TM), and an intracellular (IC) domain (Figure 1A,B). The EC domain of human Cdh1 shares 78-95\% sequence identity and 85-97\% similarity (Table 2). Comparing the amino acid sequences of Cdh1 orthologues, a high degree of conservation in the calcium binding sites was revealed (Figure 1B, highlighted in green), while more sequence variability was found in the linker regions (Figure 1B, highlighted in red). The conserved [VITA]-[VITA]-x-x-D-[DN] sequence pattern in calcium binding sites was initially identified as important signature motifs for $H$. pylori HtrA cleavage leading to a unique fragmentation pattern of Cdh1 [31]. However, in tissues with intact intercellular adhesions, these sites are masked by bound calcium ions, which efficiently prevents the fragmentation of the extracellular domain of Cdh1 [31,32]. The amino acid sequence $A Q P V \downarrow$ EAG within the linker region (Figure 1B, highlighted in red) was recently determined as a potent HtrA cleavage site targeted by $H$. pylori during infection. Cleavage after the hydrophobic valine in position P1 was identified to be responsible for 
the formation of the soluble $90 \mathrm{kDa}$ fragment observed after H. pylori infection of polarized gastric epithelial cells [33], suggesting that this site is the major site in the extracellular E-cadherin domain for HtrA proteases. However, this cleavage site in the linker region of E-cadherin exhibits sequence variations in Cdh1 orthologues from humans, monkeys, mice, and dogs (Figure 1B), implying that HtrA targets E-cadherin orthologues with altered efficiency in these species.

Table 2. Comparison of the extracellular domain of Cdh1 orthologues.

\begin{tabular}{cccccc}
\hline Name & UniProt No. & Gene & Species & \% Identity & \% Similarity \\
\hline E-cadherin & P12830 & CDH1 & Homo sapiens & 100 & 100 \\
E-cadherin & A0A2K5V299 & CDH1 & Macaca fascicularis & 95 & 97 \\
E-cadherin & F1PAA9 & CDH1 & Canis lupus familiaris & 79 & 87 \\
E-cadherin & P09803 & CDH1 & Mus musculus & 78 & 85
\end{tabular}

${ }^{1}$ Sequence alignment was performed for the annotated extracellular domain of Cdh1 proteins including the signal peptide and pro-peptide.

A

(SPCC

B

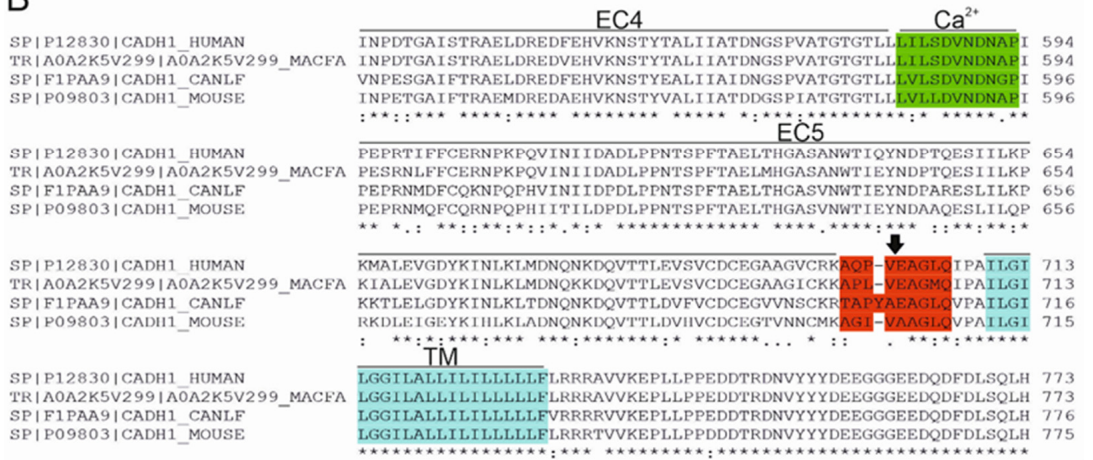

Figure 1. Cdh1 orthologues share high sequence homologies in HtrA cleavage sites. (A) Models of the domain structure of the Cdh1 expressed by Homo sapiens (Hs), Macaca fascicularis (Mf), Canis lupus familiaris $(\mathrm{Cl})$ and $\mathrm{Mus}$ musculus $(\mathrm{Mm})$. Calcium binding regions are located in between the EC domains with calcium ions shown as yellow spheres. SP, signal peptide; PP, pro-peptide; EC, extracellular domain; TM, transmembrane domain; IC, intracellular domain. (B) Alignment of the amino acid sequence of Cdh1 orthologues spanning the region between the EC4, HtrA signature sites (highlighted in green), EC5, linker region (highlighted in red), identified HtrA cleavage site (black arrow), and the TM domain (highlighted in blue).

For the experimental analyses of HtrA-mediated cleavage of these Cdh1 orthologues, recombinant proteins with the characteristic glycosylation patterns of the native proteins were required. Sequences encoding the extracellular Cdh1 domains, including SP and PP, but lacking the TM and IC domains were cloned into eukaryotic expression systems to generate secreted and glycosylated Cdh1 orthologues fused to a C-terminal GST-His 6 -tag (Figure 2A). Human gastric epithelial AGS cells lacking endogenous Cdh1 expression [34] were transiently transfected and Cdh1-GST-His 6 proteins were purified from the supernatants. Next, $100 \mathrm{ng}$ of purified recombinant Mf (Figure 2B), Cl (Figure 2C), or Mm Cdh1 
(Figure 2D) was incubated for $16 \mathrm{~h}$ with increasing amounts of recombinant $H$. pylori HtrA wild type (wt), which serves as a prime examples for active HtrA protease. Hs Cdh1 was also included in this study, serving as a well-established reference (Figure 2E). As negative controls, Cdh1 proteins were incubated without HtrA (-) or with 1000 ng proteolytic inactive HtrA $\mathrm{S}_{221} \mathrm{~A}$ (SA) (Figure 2B-E, lanes 1 and 8). Also, $1000 \mathrm{ng}$ HtrA wt served as control for antibody cross reaction (Figure 2B-E, lane 9). Compared to Hs Cdh1 (Figure 2E), high concentrations of HtrA were necessary to induce $M f$ Cdh1 cleavage (Figure 2B). The strongest effect was observed after incubation of $M f C d h 1$ with 1000 ng of HtrA as reflected by the decrease of full-length $M f \mathrm{Cdh} 1\left(M f \mathrm{Cdh}^{\mathrm{FL}}\right)$ (Figure 2B, compare lanes 2-7 with lanes 1 and 8). In contrast, low concentrations of HtrA were sufficient to cleave $\mathrm{Cl}$ and $\mathrm{Mm}$ $\mathrm{Cdh} 1^{\mathrm{FL}}$, which was further enhanced using increasing amounts of HtrA (Figure 2C,D). The signals from Western blot analyses were quantitated from three independent experiments and confirmed the efficient HtrA cleavage activity using $\mathrm{Hs}, \mathrm{Cl}$, and $\mathrm{Mm} \mathrm{Cdh} 1$ as substrates, and the lower activity towards $M f \mathrm{Cdh} 1$ (Figure 2F). This result is unexpected, as $M f \mathrm{Cdh} 1$ and $H s$ Cdh1 show the strongest homology. Nevertheless, individual changes of amino acids in the EC domain may influence the accessibility of Cdh1 for HtrA, affecting the in vitro cleavage activity.

A

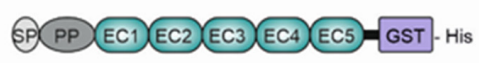

C

- 으융유융유응은 HtrA[ng]

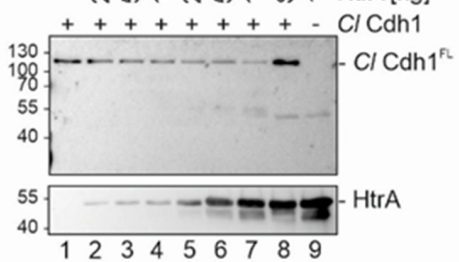

E

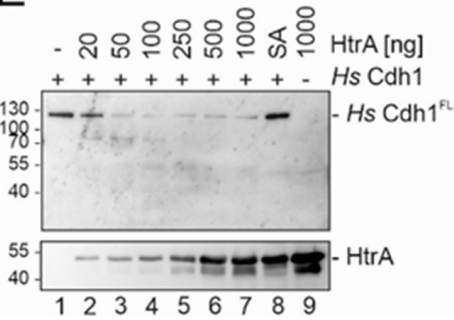

B

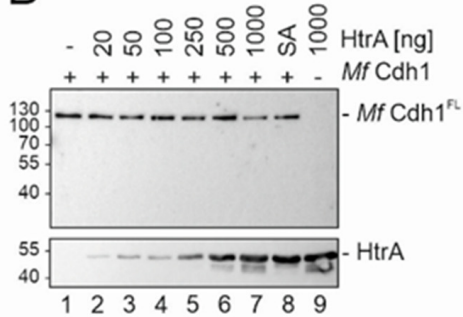

$\mathrm{D}$

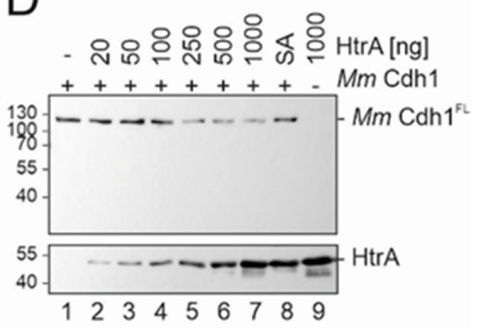

$\mathrm{F}$

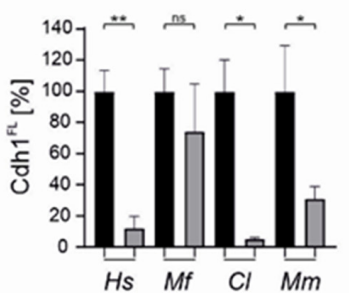

Figure 2. Cdh1 variants are efficiently cleaved by HtrA. (A) Scheme of the recombinant Cdh1 proteins. $100 \mathrm{ng}$ of recombinant $M f \mathrm{Cdh} 1$ (B), $\mathrm{Cl} \mathrm{Cdh} 1$ (C), Mm Cdh1 (D), and Hs Cdh1 (E) were incubated with the indicated amounts of recombinant active HtrA for $16 \mathrm{~h}$ at $37^{\circ} \mathrm{C}$ (lanes 2-7). As a control, recombinant Cdh1 were incubated with $1000 \mathrm{ng}$ of inactive HtrA (SA, lane 8) or left untreated (lane 1). To control possible antibody cross-reactions, HtrA alone was loaded (lane 9). The different Cdh1 full-length (FL) versions were detected using an antibody recognizing the C-terminal $\mathrm{His}_{6}$-tag. HtrA was detected by using a polyclonal HtrA antibody. (F) The amount of Cdh1 $1^{\mathrm{FL}}$ treated with $1000 \mathrm{ng}$ recombinant active HtrA (grey) or inactive HtrA (black) was quantified by blot densitometry. Data are presented as percent means of $\mathrm{Cad}^{\mathrm{FL}} \pm \mathrm{SD}(n=3)$, with the cadherin treated with the inactive HtrA set at $100 \%$ and compared with the signal intensity of $\mathrm{Cdh} 1^{\mathrm{FL}}$ treated with $1000 \mathrm{ng}$ of active HtrA. Asterisks indicate statistically significant differences $\left({ }^{* *} p<0.01{ }^{*} p<0.05\right.$; ns, not significant). 
These findings were further investigated through the analysis of the kinetics of proteolytic activities by additional in vitro cleavage experiments. Recombinant $\mathrm{Mf}, \mathrm{Cl}$, and $\mathrm{Mm}$ Cdh1 were incubated with $250 \mathrm{ng} \mathrm{HtrA}$ for the indicated periods of time (Figure 3A-C) and compared to the kinetics of HtrA-mediated Hs Cdh1 cleavage (Figure 3D). Again, the amount of $M f C d h 1^{\mathrm{FL}}$ only weakly decreased after incubation with HtrA (Figure 3A). Even after $16 \mathrm{~h}$ there was no significant difference between HtrA wt and HtrA SA treated $M f \mathrm{Cdh} 1$ (Figure 3A,E). Considering $\mathrm{Cl} \mathrm{Cdh} 1^{\mathrm{FL}}$ (Figure 3B) and $\mathrm{Mm} \mathrm{Cdh} 1^{\mathrm{FL}}$ (Figure 3C), a strong decrease could be observed already after one hour of incubation with HtrA (Figure 3B,C, lanes 6 and 7). Quantification demonstrated statistically significant HtrA wt-mediated $\mathrm{Cl} \mathrm{Cdh} 1$ and $\mathrm{Mm} \mathrm{Cdh} 1$ cleavage compared to the treatment with the inactive HtrA SA after $16 \mathrm{~h}$ (Figure 3E). The kinetics and the extent of HtrA-mediated cleavage of $\mathrm{Cl}$ Cdh1 and $\mathrm{Mm}$ Cdh1 were comparable to HtrA-mediated cleavage of Hs Cdh1, which was included as a control (Figure 3D,E).
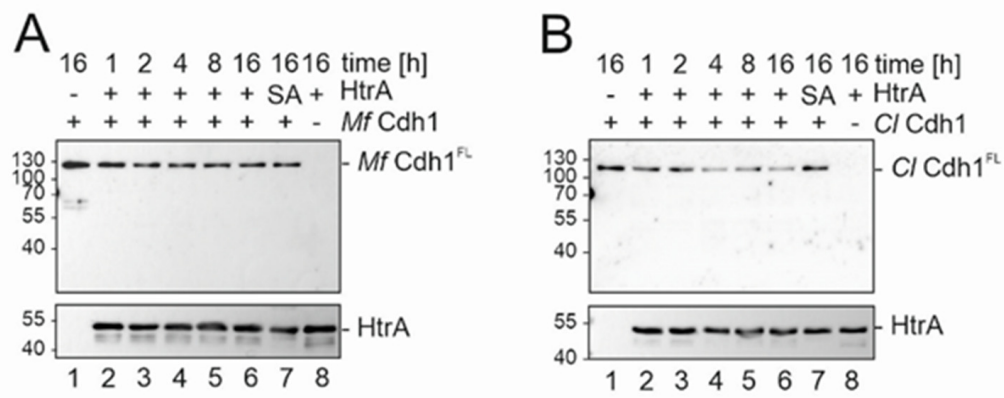

C

$\begin{array}{lllllll}16 & 1 & 2 & 4 & 8 & 16 & 1616 \\ & -1 i m e & {[\mathrm{~h}]}\end{array}$

$-+++++\mathrm{SA}+\mathrm{HtrA}$

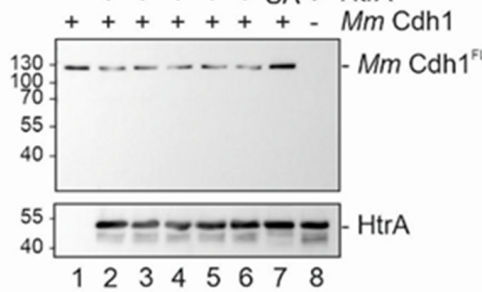

D
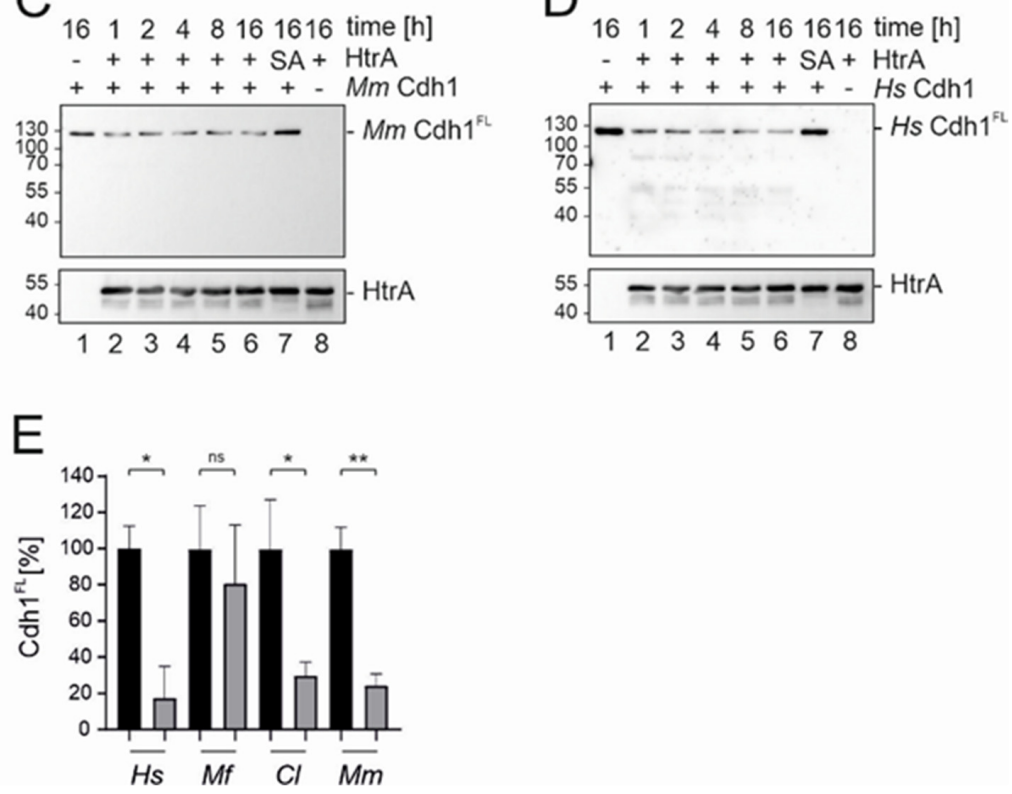

Figure 3. Kinetics of HtrA-mediated Cdh1 cleavage. $100 \mathrm{ng}$ of recombinant $M f \mathrm{Cdh} 1$ (A), $\mathrm{Cl} \mathrm{Cdh} 1$ (B), $M m \mathrm{Cdh} 1$ (C), and $\mathrm{Hs} \mathrm{Cdh} 1$ (D) were incubated with $250 \mathrm{ng}$ recombinant active HtrA for the indicated time points at $37^{\circ} \mathrm{C}$ (lanes 2-6). As a control, recombinant $\mathrm{Cdh} 1$ was incubated for $16 \mathrm{~h}$ with inactive HtrA (SA, lane 7) or left untreated (lane 1). To control antibody cross-reactions, HtrA alone was loaded (lane 8). The different $\mathrm{Cdh} 1^{\mathrm{FL}}$ variants were detected using an antibody recognizing the C-terminal His $_{6}$-tag. HtrA was detected using a polyclonal HtrA antibody. (E) The amount of Cdh1 ${ }^{\mathrm{FL}}$ treated for $16 \mathrm{~h}$ with recombinant active HtrA (grey) or inactive HtrA SA (black) was quantified by blot densitometry. Data are presented as percent means of $\mathrm{Cad}^{\mathrm{FL}} \pm \mathrm{SD}(n=3)$, with the cadherin treated with the inactive HtrA SA set at $100 \%$ and compared with the signal intensity of Cdh1 ${ }^{\mathrm{FL}}$ treated with active HtrA for $16 \mathrm{~h}$. Asterisks indicate statistically significant differences $\left({ }^{* *} p<0.01\right.$; * $p<0.05 ;$ ns, not significant). 


\subsection{Cleavage of Orthologous E-Cadherin after Infection of Epithelial Cells}

In vitro cleavage experiments certainly do not reflect the physiological situation during infection, which is strongly influenced by the dynamic and complex structure of the adhesion complexes. Hence, we investigated the cleavage of Cdh1 orthologues in a bacterial infection model using the H. pylori wt strain P12 and N6, an isogenic N6 htrA deletion mutant (N6 $\Delta$ ) and an $h t r A$-complemented mutant (N6 $\Delta / \mathrm{wt}$ ) [27]. Genomic deletion of $h t r A$ genes in pathogens has frequently been associated with a less pathogenic phenotype $[35,36]$. Hence, MKN-28 cells were infected with $H$. pylori strains followed by immunofluorescence staining using an anti-H. pylori serum. Super-resolution imaging using a STED microscope revealed a rod-shaped morphology for P12 wt, N6 wt, and N6 $\Delta$ /wt as expected, but a coccoid phenotype of N6 $\Delta$ (Figure 4A). This observation suggests that HtrA might play a determinant role in bacterial morphology either through absence of the periplasmic chaperone function of HtrA or through direct processing of bacterial factors, which are important for the cellular phenotype. An effect of HtrA proteases on bacterial cell shape was described for Mycobacterium smegmatis [37] and the cyanobacterium Synechocystis sp. PCC 6803, where the deletion of the htrA gene caused a defect in the biosynthesis of the outer cell layers [38]. Hence, further investigations are necessary to examine the impact of $\mathrm{HtrA}$ on the regulation of the cell wall.

HtrA expression has repeatedly been associated with bacterial adhesions to host cells $[35,36]$. We observed only a slight effect of $\mathrm{H}$. pylori HtrA expression on the adherence to MKN-28 cells (Figure 4B) indicating that the htrA knockout mutant can equally well colonize epithelial cells as previously demonstrated [28]. To analyze the impact of HtrApositive $\mathrm{H}$. pylori on cleavage of Cdh1 orthologues, we established a novel infection model using the partially polarized gastric epithelial cell line MKN-28. The endogenous Cdh1 expression was interrupted by CRISPR/Cas9-mediated genomic deletion of the hcdh1 gene and orthologous Cdh1 proteins were stably re-expressed with full-length $\mathrm{Hs}, \mathrm{Mf}, \mathrm{Cl}$, or Mm CDH1 genes fused to a C-terminal GFP tag (Figure 4C). We then investigated the Cdh1 fragments of variants in whole cell lysates of MKN-28 cells after colonization with the H. pylori strains P12 wt, N6 wt, N6 $\Delta$, as well as N6 $\Delta$ /wt [27]. We observed a strong cleavage of Mf Cdh1 after infection with HtrA-positive $\mathrm{H}$. pylori strains, which resulted in the reduction of full-length $\mathrm{Mf} \mathrm{Cdh} 1$ and the appearance of the C-terminal fragments CFT1 and CTF2 [17]. The detected fragmentation pattern of Cdh1 is characteristic for H. pylori infections. Full-length Cdh1FL can be cleaved in a soluble extracellular domain N-terminal fragment, which is dependent on HtrA and largely independent of host proteases [17,21]. Removal of the extracellular E-cadherin domain generates a membrane-anchored $40 \mathrm{kDa}$ C-terminal fragment CTF1, which can be further processed by intracellular host proteases into a soluble $33 \mathrm{kDa}$ CTF2 fragment [39]. Calpain was identified to induce a specific, inactivating proteolytic cleavage within the cytoplasmic domain of Cdh1 in prostate and mammary epithelial cells [40]. Since H. pylori can activate calpain [41], we assume that activated calpain mediates the intracellular cleavage of Cdh1.

Importantly, infection with N6 $\Delta h t r A$ mutant did not fragment $M f C d h 1$, while the complemented N6 $\Delta$ /wt enhanced $M f C$ dh1 cleavage (Figure 4C, upper left panel), which is in a slight contrast to the in vitro cleavage experiments. The discrepancy between these data cannot be simply explained by the HtrA cleavage sites in the calcium binding site or the linker regions, which are highly homologous to $\mathrm{Hs} \mathrm{Cdh} 1$ (Figure 1B). It has been well established that the binding of calcium to Cdh1 and formation of homophilic interactions of the ectodomains in cis and trans elongate the curved Cdh1 structure, forming a threedimensional extracellular net of interacting ectodomains [2,42]. Therefore, we propose that the conformation and structure of Cdh1 proteins are important aspects in the recognition of Cdh1 by HtrA on the cell surface. Similar results were observed for the infection of MKNK28 cells expressing either $\mathrm{Cl} C \mathrm{Cdh} 1$ (Figure 4C, upper right panel), $\mathrm{Mm} \mathrm{Cdh} 1$ (Figure 4C, lower left panel), or $\mathrm{Hs}$ Cdh1 (Figure 4C, lower right panel), which was included as a control. Detection of HtrA was performed to verify HtrA expression in H. pylori strain. 
CagA was detected as a control for equal bacterial adherence and GAPDH served as a loading control (Figure 4C).

\section{A}

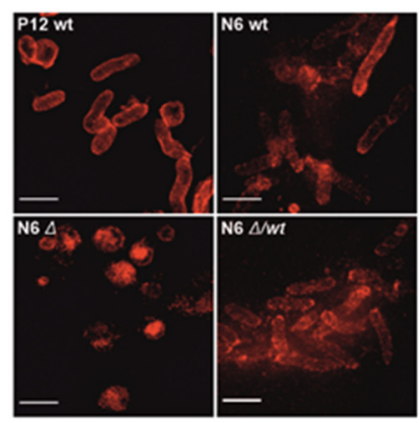

B

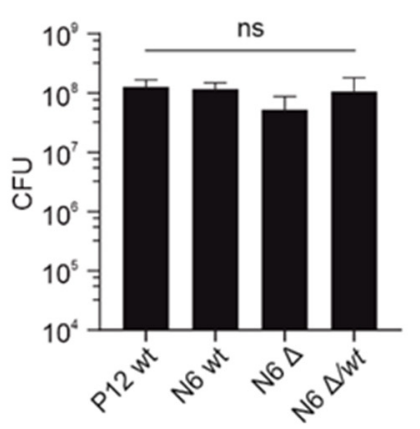

C
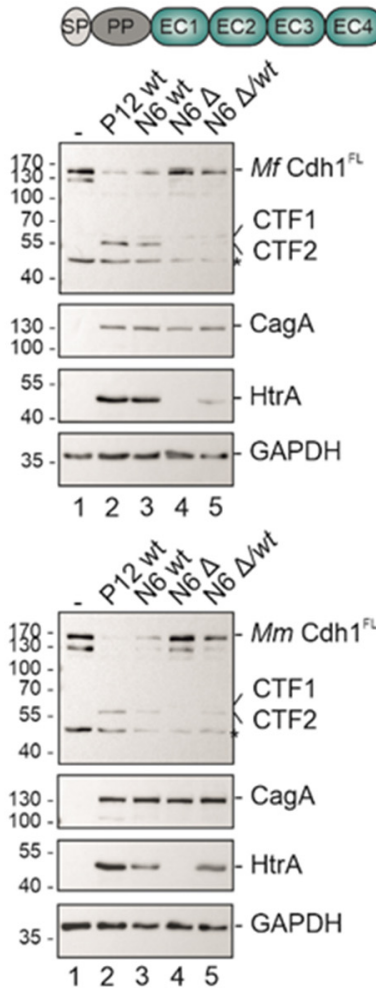
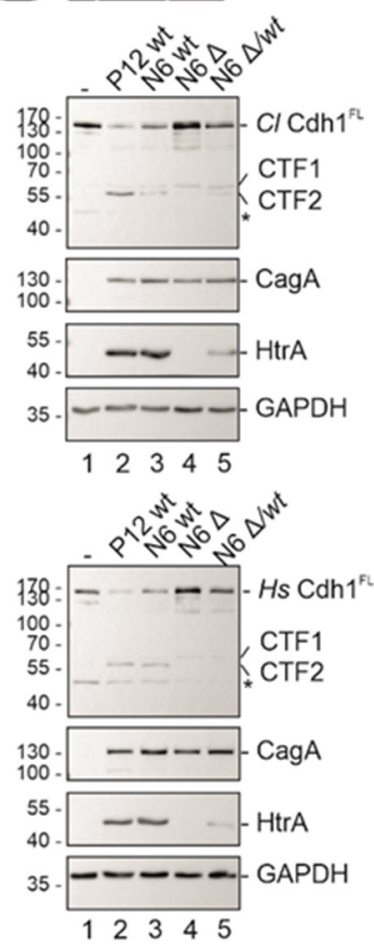
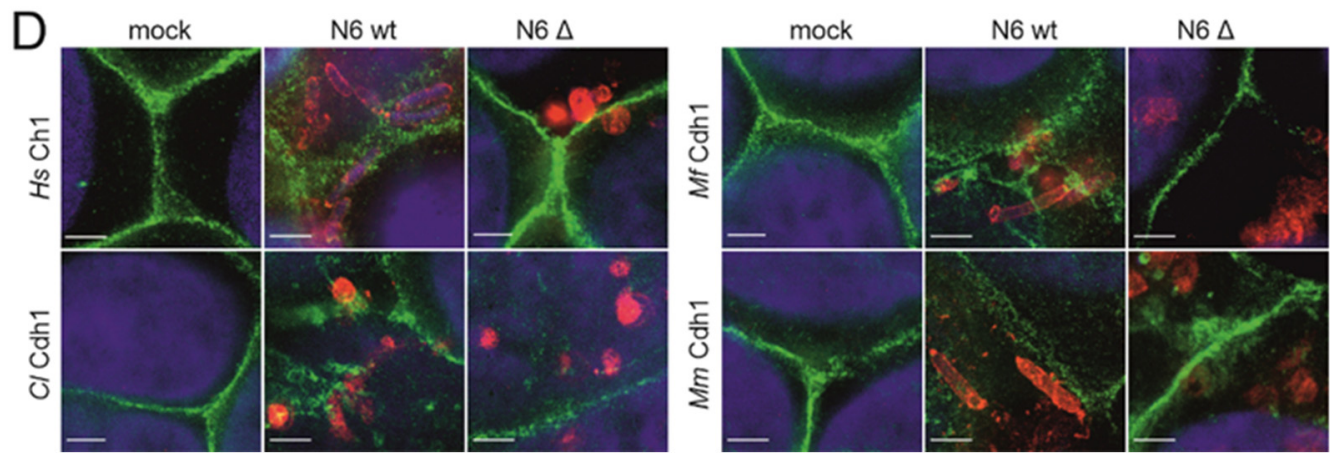

Figure 4. Infection of gastric epithelial cells expressing Cdh1 orthologues. (A) Representative STED images of $H$. pylori P12 wt, N6 wt, N6 $\Delta h t r A$, and N6 $\Delta h t r A / h t r A w t$ bacteria attached to gastric epithelial cells stained using a polyclonal serum raised against $H$. pylori lysate. Scale bar, $2 \mu \mathrm{m}$. (B) MKN-28 wt cells were infected with H. pylori P12 wt, N6 wt, N6 $\Delta h t r A$, and N6 $\Delta h t r A / h t r A$ wt for $6 \mathrm{~h}$ and the number of bacterial cells adhering to MKN-28 cells was quantified and are presented as mean values $\pm \mathrm{SD}(n=4)$. CFU, colony forming unit; ns, not significant. (C) MKN-28 cells stably expressing Cdh1 proteins as indicated were infected with $H$. pylori P12 wt, N6 wt, N6 $\Delta h t r A$, and N6 $\Delta h t r A / h t r A$ wt for $24 \mathrm{~h}$. Non-infected cells served as control. Whole cell lysates of infected cells were analyzed by Western blotting for Cdh1 full length $\left(\mathrm{Cdh}^{\mathrm{FL}}\right)$ and the C-terminal fragments CFT1 and CTF2 using an antibody recognizing the intracellular domain of Cdh1 (first panel). CagA and HtrA were detected as loading controls for H. pylori (second and third panel). Loading control for MKN-28 cells was performed by detection of GAPDH (fourth panel). *, unspecific band. (D) Representative STED images of MKN-28 cells stably expressing Cdh1 proteins (green) derived from $\mathrm{Hs}, \mathrm{Mf}, \mathrm{Cl}$, and $M m$ infected with $H$. pylori N6 wt and N6 $\Delta h t r A$ bacteria (red), or uninfected controls (mock); Nuclei were stained using DAPI (blue). Scale bars, $2 \mu \mathrm{m}$. 
The consequences of Cdh1 cleavage were verified by super-resolution microscopy to monitor the changed localization of $\mathrm{Cdh} 1$ proteins upon infection with HtrA-positive bacteria. Intact Cdh1-based adherens junctions are membrane-located and the loss of the ectodomain of Cdh1 leads to a disintegration of the Cdh1 complex followed by the internalization of the intracellular Cdh1 domain in vesicles [43]. Stably expressing Cdh1GFP MKN-28 cells were infected with $H$. pylori wt or the isogenic $h t r A$ deletion mutant and the cellular distribution of $H s \mathrm{Cdh} 1, M f \mathrm{Cdh} 1, \mathrm{Cl} \mathrm{Cdh1}$, and Mm Cdh1 was analyzed (Figure 4D). In non-infected cells, Cdh1 proteins were clearly located in the cell membrane. After infection with $H$. pylori wt, membrane localization of Cdh1 proteins was lost or became highly diffuse at sites where bacteria attached to cells. These data imply that HtrAmediated cleavage is a local process and can mainly be observed in the direct vicinity of the bacteria. Cdh1 proteins appear in speckles indicating internalization of truncated Cdh1 CTFs in vesicles [43]. If truncated CTF fragments are internalized after HtrA-mediated shedding from the cell surface or after additional cleavage of the intracellular domain via calpain is not known, but will be investigated in the future.

\section{Conclusions}

In this study it was shown that HtrA targets Cdh1 orthologues from Macaca fascicularis, Canis lupus familiaris, and Mus muculus to a similar extent as human Cdh1. H. pylori is a human pathogen that exclusively colonizes human stomachs, but a large number of non-H. pylori species were detected in animals, which were not extensively studied yet. In conclusion, HtrA proteins are highly conserved in the Helicobacter genus. Therefore, we propose that HtrA-mediated Cdh1 shedding is a relevant process in the pathogenesis induced by other Helicobacter species in non-human organisms.

Author Contributions: Conceptualization, S.B., G.P., U.Z., J.S.-G. and S.W.; Methodology, S.B., E.H., T.P.S., M.H., U.Z. and I.W.; Validation, S.B., I.W. and E.H.; Writing S.B., E.H., G.P. and S.W.; Project Administration, J.S.-G., G.P. and S.W.; Funding Acquisition, S.W. All authors have read and agreed to the published version of the manuscript.

Funding: The work of SW was supported by the grants I_4360 and P_31507 from the Austrian Science Fund (FWF).

Institutional Review Board Statement: Not applicable.

Informed Consent Statement: Not applicable.

Data Availability Statement: Data available on request from the authors.

Acknowledgments: We thank Rainer Haas (Max von Pettenkofer-Institute, Munich, Germany) for the anti-H. pylori serum. Open Access Funding by the Austrian Science Fund (FWF).

Conflicts of Interest: The authors declare no conflict of interest.

\section{References}

1. Hoffman, B.D.; Yap, A.S. Towards a dynamic understanding of cadherin-based mechanobiology. Trends Cell Biol. 2015, 25, 803-814. [CrossRef] [PubMed]

2. Pertz, O.; Bozic, D.; Koch, A.W.; Fauser, C.; Brancaccio, A.; Engel, J. A new crystal structure, Ca ${ }^{2+}$ dependence and mutational analysis reveal molecular details of E-cadherin homoassociation. EMBO J. 1999, 18, 1738-1747. [CrossRef]

3. Makagiansar, I.T.; Nguyen, P.D.; Ikesue, A.; Kuczera, K.; Dentler, W.; Urbauer, J.L.; Galeva, N.; Alterman, M.; Siahaan, T.J. Disulfide bond formation promotes the cis- and trans-dimerization of the E-cadherin-derived first repeat. J. Biol. Chem. 2002, 277, 16002-16010. [CrossRef] [PubMed]

4. Van der Wal, T.; van Amerongen, R. Walking the tight wire between cell adhesion and WNT signalling: A balancing act for $\beta$-catenin. Open Biol. 2020, 10, 200267. [CrossRef]

5. Venhuizen, J.H.; Jacobs, F.J.C.; Span, P.N.; Zegers, M.M. P120 and E-cadherin: Double-edged swords in tumor metastasis. Semin. Cancer Biol. 2020, 60, 107-120. [CrossRef] [PubMed]

6. Ozawa, M.; Kemler, R. The membrane-proximal region of the E-cadherin cytoplasmic domain prevents dimerization and negatively regulates adhesion activity. J. Cell Biol. 1998, 142, 1605-1613. [CrossRef] [PubMed] 
7. Shibamoto, S.; Hayakawa, M.; Takeuchi, K.; Hori, T.; Oku, N.; Miyazawa, K.; Kitamura, N.; Takeichi, M.; Ito, F. Tyrosine phosphorylation of beta-catenin and plakoglobin enhanced by hepatocyte growth factor and epidermal growth factor in human carcinoma cells. Cell Adhes. Commun. 1994, 1, 295-305. [CrossRef]

8. Mareel, M.; Bracke, M.; Van Roy, F. Cancer metastasis: Negative regulation by an invasion-suppressor complex. Cancer Detect. Prev. 1995, 19, 451-464.

9. Hiraguri, S.; Godfrey, T.; Nakamura, H.; Graff, J.; Collins, C.; Shayesteh, L.; Doggett, N.; Johnson, K.; Wheelock, M.; Herman, J.; et al. Mechanisms of inactivation of E-cadherin in breast cancer cell lines. Cancer Res. 1998, 58, 1972-1977.

10. Noë, V.; Fingleton, B.; Jacobs, K.; Crawford, H.C.; Vermeulen, S.; Steelant, W.; Bruyneel, E.; Matrisian, L.M.; Mareel, M. Release of an invasion promoter E-cadherin fragment by matrilysin and stromelysin-1. J. Cell Sci. 2001, 114, 111-118. [CrossRef]

11. Maretzky, T.; Reiss, K.; Ludwig, A.; Buchholz, J.; Scholz, F.; Proksch, E.; de Strooper, B.; Hartmann, D.; Saftig, P. ADAM10 mediates E-cadherin shedding and regulates epithelial cell-cell adhesion, migration, and beta-catenin translocation. Proc. Natl. Acad. Sci. USA 2005, 102, 9182-9187. [CrossRef] [PubMed]

12. Rawlings, N.D.; Morton, F.R.; Kok, C.Y.; Kong, J.; Barrett, A.J. MEROPS: The peptidase database. Nucleic Acids Res. 2008, 36, D320-D325. [CrossRef] [PubMed]

13. Waller, P.R.; Sauer, R.T. Characterization of degQ and degS, Escherichia coli genes encoding homologs of the DegP protease. J Bacteriol. 1996, 178, 1146-1153. [CrossRef] [PubMed]

14. Hansen, G.; Hilgenfeld, R. Architecture and regulation of HtrA-family proteins involved in protein quality control and stress response. Cell Mol. Life Sci. 2013, 70, 761-775. [CrossRef]

15. Kim, D.Y.; Kim, K.K. Structure and function of HtrA family proteins, the key players in protein quality control. J. Biochem. Mol. Biol. 2005, 38, 266-274. [CrossRef]

16. Jiang, J.; Zhang, X.; Chen, Y.; Wu, Y.; Zhou, Z.H.; Chang, Z.; Sui, S.F. Activation of DegP chaperone-protease via formation of large cage-like oligomers upon binding to substrate proteins. Proc. Natl. Acad. Sci. USA 2008, 105, 11939-11944. [CrossRef]

17. Hoy, B.; Löwer, M.; Weydig, C.; Carra, G.; Tegtmeyer, N.; Geppert, T.; Schröder, P.; Sewald, N.; Backert, S.; Schneider, G.; et al Helicobacter pylori HtrA is a new secreted virulence factor that cleaves E-cadherin to disrupt intercellular adhesion. EMBO Rep. 2010, 11, 798-804. [CrossRef]

18. Harrer, A.; Boehm, M.; Backert, S.; Tegtmeyer, N. Overexpression of serine protease HtrA enhances disruption of adherens junctions, paracellular transmigration and type IV secretion of CagA by Helicobacter pylori. Gut Pathog. 2017, 9, 40. [CrossRef]

19. Hoy, B.; Brandstetter, H.; Wessler, S. The stability and activity of recombinant Helicobacter pylori HtrA under stress conditions. $J$. Basic Microbiol. 2013, 53, 402-409. [CrossRef]

20. Tegtmeyer, N.; Wessler, S.; Necchi, V.; Rohde, M.; Harrer, A.; Rau, T.T.; Asche, C.I.; Boehm, M.; Loessner, H.; Figueiredo, C.; et al. Helicobacter pylori employs a unique basolateral Type IV secretion mechanism for CagA delivery. Cell Host Microbe 2017, 22, 552-560. [CrossRef]

21. Bernegger, S.; Vidmar, R.; Fonovic, M.; Posselt, G.; Turk, B.; Wessler, S. Identification of Desmoglein-2 as a novel target of Helicobacter pylori HtrA in epithelial cells. Cell Commun. Signal. 2021, 19, 108. [CrossRef]

22. Boehm, M.; Hoy, B.; Rohde, M.; Tegtmeyer, N.; Bæk, K.T.; Oyarzabal, O.A.; Brøndsted, L.; Wessler, S.; Backert, S. Rapid paracellular transmigration of Campylobacter jejuni across polarized epithelial cells without affecting TER: Role of proteolytic-active HtrA cleaving E-cadherin but not fibronectin. Gut Pathog. 2012, 4, 3. [CrossRef] [PubMed]

23. Hoy, B.; Geppert, T.; Boehm, M.; Reisen, F.; Plattner, P.; Gadermaier, G.; Sewald, N.; Ferreira, F.; Briza, P.; Schneider, G.; et al. Distinct roles of secreted HtrA proteases from gram-negative pathogens in cleaving the junctional protein and tumor suppressor E-cadherin. J. Biol. Chem. 2012, 287, 10115-10120. [CrossRef] [PubMed]

24. Abfalter, C.M.; Schubert, M.; Götz, C.; Schmidt, T.P.; Posselt, G.; Wessler, S. HtrA-mediated E-cadherin cleavage is limited to DegP and DegQ homologs expressed by gram-negative pathogens. Cell Commun. Signal. 2016, 14, 30. [CrossRef] [PubMed]

25. Löwer, M.; Weydig, C.; Metzler, D.; Reuter, A.; Starzinski-Powitz, A.; Wessler, S.; Schneider, G. Prediction of extracellular proteases of the human pathogen helicobacter pylori reveals proteolytic activity of the Hp1018/19 protein HtrA. PLoS ONE 2008, 3, e3510. [CrossRef] [PubMed]

26. Cong, L.; Ran, F.A.; Cox, D.; Lin, S.; Barretto, R.; Habib, N.; Hsu, P.D.; Wu, X.; Jiang, W.; Marraffini, L.A.; et al. Multiplex genome engineering using CRISPR/Cas systems. Science 2013, 339, 819-823. [CrossRef] [PubMed]

27. Zawilak-Pawlik, A.; Zarzecka, U.; Żyła-Uklejewicz, D.; Lach, J.; Strapagiel, D.; Tegtmeyer, N.; Böhm, M.; Backert, S.; SkorkoGlonek, J. Establishment of serine protease htrA mutants in Helicobacter pylori is associated with secA mutations. Sci. Rep. 2019, 9, 11794. [CrossRef]

28. Zarzecka, U.; Modrak-Wójcik, A.; Figaj, D.; Apanowicz, M.; Lesner, A.; Bzowska, A.; Lipinska, B.; Zawilak-Pawlik, A.; Backert, S.; Skorko-Glonek, J. Properties of the HtrA protease from bacterium helicobacter pylori whose activity is indispensable for growth under stress conditions. Front. Microbiol. 2019, 10, 961. [CrossRef]

29. Overduin, M.; Harvey, T.; Bagby, S.; Tong, K.; Yau, P.; Takeichi, M.; Ikura, M. Solution structure of the epithelial cadherin domain responsible for selective cell adhesion. Science 1995, 267, 386-389. [CrossRef] [PubMed]

30. Shapiro, L.; Fannon, A.M.; Kwong, P.D.; Thompson, A.; Lehmann, M.S.; Grübel, G.; Legrand, J.-F.; Als-Nielsen, J.; Colman, D.R.; Hendrickson, W.A. Structural basis of cell-cell adhesion by cadherins. Nature 1995, 374, 327-337. [CrossRef] [PubMed] 
31. Schmidt, T.P.; Perna, A.M.; Fugmann, T.; Böhm, M.; Jan, H.; Haller, S.; Götz, C.; Tegtmeyer, N.; Hoy, B.; Rau, T.T.; et al. Identification of E-cadherin signature motifs functioning as cleavage sites for Helicobacter pylori HtrA. Sci. Rep. 2016, 6, 23264. [CrossRef] [PubMed]

32. Schmidt, T.P.; Goetz, C.; Huemer, M.; Schneider, G.; Wessler, S. Calcium binding protects E-cadherin from cleavage by Helicobacter pylori HtrA. Gut Pathog. 2016, 8, 29. [CrossRef] [PubMed]

33. Bernegger, S.; Brunner, C.; Vizovišek, M.; Fonovic, M.; Cuciniello, G.; Giordano, F.; Stanojlovic, V.; Jarzab, M.; Simister, P.; Feller, S.M.; et al. A novel FRET peptide assay reveals efficient Helicobacter pylori HtrA inhibition through zinc and copper binding. Sci. Rep. 2020, 10, 10563. [CrossRef] [PubMed]

34. Hsieh, M.C.; Wu, C.W.; Wu, L.H.; Lui, W.Y.; P'Eng, F.K.; Yu, C.L. Heat shock and cytokines modulate the expression of adhesion molecules on different human gastric-cancer cell lines. Int. J. Cancer 1996, 67, 690-694. [CrossRef]

35. Bakker, D.; Buckley, A.M.; de Jong, A.; van Winden, V.J.; Verhoeks, J.P.; Kuipers, O.P.; Douce, G.R.; Kuijper, E.J.; Smits, W.K.; Corver, J. The HtrA-like protease CD3284 modulates virulence of Clostridium difficile. Infect. Immun. 2014, 82, $4222-4232$. [CrossRef]

36. Simson, D.; Boehm, M.; Backert, S. HtrA-dependent adherence and invasion of Campylobacter jejuni in human vs. avian cells. Lett. Appl. Microbiol. 2020, 70, 326-330. [CrossRef]

37. $\mathrm{Wu}, \mathrm{K} . J . ;$ Boutte, C.C.; Ioerger, T.R.; Rubin, E.J. Mycobacterium smegmatis HtrA blocks the toxic activity of a putative cell wall amidase. Cell Rep. 2019, 27, 2468-2479.e3. [CrossRef]

38. Cheregi, O.; Miranda, H.; Gröbner, G.; Funk, C. Inactivation of the Deg protease family in the cyanobacterium Synechocystis sp. PCC 6803 has impact on the outer cell layers. J. Photochem. Photobiol. B 2015, 152, 383-394. [CrossRef]

39. Marambaud, P.; Shioi, J.; Serban, G.; Georgakopoulos, A.; Sarner, S.; Nagy, V.; Baki, L.; Wen, P.; Efthimiopoulos, S.; Shao, Z.; et al A presenilin-1/gamma-secretase cleavage releases the E-cadherin intracellular domain and regulates disassembly of adherens junctions. EMBO J. 2002, 21, 1948-1956. [CrossRef]

40. Rios-Doria, J.; Day, K.C.; Kuefer, R.; Rashid, M.G.; Chinnaiyan, A.M.; Rubin, M.A.; Day, M.L. The role of calpain in the proteolytic cleavage of E-cadherin in prostate and mammary epithelial cells. J. Biol. Chem. 2003, 278, 1372-1379. [CrossRef]

41. O'Connor, P.M.; Lapointe, T.K.; Jackson, S.; Beck, P.L.; Jones, N.L.; Buret, A.G. Helicobacter pylori activates calpain via toll-like receptor 2 to disrupt adherens junctions in human gastric epithelial cells. Infect. Immun. 2011, 79, 3887-3894. [CrossRef] [PubMed]

42. Harrison, O.J.; Jin, X.; Hong, S.; Bahna, F.; Ahlsen, G.; Brasch, J.; Wu, Y.; Vendome, J.; Felsovalyi, K.; Hampton, C.M.; et al. The extracellular architecture of adherens junctions revealed by crystal structures of type I cadherins. Structure 2011, 19, 244-256. [CrossRef] [PubMed]

43. Weydig, C.; Starzinski-Powitz, A.; Carra, G.; Löwer, J.; Wessler, S. CagA-independent disruption of adherence junction complexes involves E-cadherin shedding and implies multiple steps in Helicobacter pylori pathogenicity. Exp. Cell Res. 2007, 313, 3459-3471. [CrossRef] [PubMed] 